\title{
Task shifting in active management of the third stage of labor: a systematic review
}

Tessa M. Raams ${ }^{*^{*}}$ D, Joyce L. Browne ${ }^{1}$, Verena J. M. M. Festen-Schrier ${ }^{1}$, Kerstin Klipstein-Grobusch ${ }^{1,2}$ and Marcus J. Rijken ${ }^{1,3}$

\begin{abstract}
Background: Active management of the third stage of labor (AMTSL) describes interventions with the common goal to prevent postpartum hemorrhage (PPH). In low- and middle-income countries, implementation of AMTSL is hampered by shortage of skilled birth attendants and a high percentage of home deliveries. Task shifting of specific AMTSL components to unskilled birth attendants or self-administration could be a strategy to increase access to potentially life-saving interventions. This study was designed to evaluate the effect, acceptance and safety of task shifting of specific aspects of AMTSL to unskilled birth attendants.
\end{abstract}

Methods: A systematic search was conducted in five databases in September 2015 to identify intervention studies of AMTSL implemented by unskilled birth attendants or pregnant women themselves. Quality of studies was evaluated with an adapted Cochrane Collaboration assessment tool.

Results: Of 2469 studies screened, 21 were included. All studies assessed implementation of uterotonics (misoprostol tablets or oxytocin injections), administered by community health workers (CHWs), auxiliary midwives, traditional birth attendants (TBAs) or self-administration at antenatal (home) visits or delivery. Task shifting for none of the other AMTSL components was reported. Task shifting of provision of uterotonics reduced the risk of PPH (RR 0.16 to 1) compared to standard care (13 studies, $n=15.197$ ). The correct dose and timing was reported for 83.4 to $99.8 \%$ ( 5 studies, $n=6083$ ) and 63 to 100\% (9 studies, $n=8378$ ) women respectively. Uterotonics were recommended to others by 80 to $99.7 \%$ (7 studies, $n=6445$ ); 80 to $99.4 \%$ (5 studies, $n=2677$ ) would use the drug at next delivery. Willingness to pay for uterotonics varied from 54.6 to $100 \%$ (7 studies, $n=6090$ ).

Conclusion: Task shifting of AMTSL has thus far been evaluated for administration of uterotonics (misoprostol tablets and oxytocin injected by CHWs and auxiliary midwives) and resulted in reduction of PPH, high rates of appropriate use and satisfaction among users.

In order to increase AMTSL coverage in low-staffed health facilities, task shifting of uterine massage or postpartum tonus assessment to unskilled attendants or delivered women could be considered. Task shifting of controlled cord traction is currently not recommended.

Keywords: Active management of the third stage of labor, Community health workers, Low- and middle-income countries, Postpartum hemorrhage, Self-administration, Task shifting, Traditional birth attendants

\footnotetext{
* Correspondence: tessa.raams@gmail.com

1 Julius Global Health, Julius Center for Health Sciences and Primary Care, University Medical Center Utrecht, Heidelberglaan 100, 3584 Utrecht, The Netherlands

Full list of author information is available at the end of the article
} International License (http://creativecommons.org/licenses/by/4.0/), which permits unrestricted use, distribution, and reproduction in any medium, provided you give appropriate credit to the original author(s) and the source, provide a link to the Creative Commons license, and indicate if changes were made. The Creative Commons Public Domain Dedication waiver (http://creativecommons.org/publicdomain/zero/1.0/) applies to the data made available in this article, unless otherwise stated. 


\section{Background}

Postpartum hemorrhage $(\mathrm{PPH})$ is the leading cause of maternal mortality worldwide and accounts for $34 \%$ of maternal deaths in low- and middle-income countries (LMIC) [1]. PPH is defined as blood loss of $500 \mathrm{ml}$ or more within $24 \mathrm{~h}$ after delivery and most frequently occurs during the third or fourth stages of labor, the period from delivery of the infant until placental delivery and $2 \mathrm{~h}$ postpartum [2]. Active management of the third stage of labor (AMTSL) describes a set of interventions aimed at the prevention of PPH [3, 4]. AMTSL includes the administration of uterotonics (for example oxytocin or misoprostol) preferably within $1 \mathrm{~min}$ after delivery to all women, controlled cord traction (CCT) to stimulate placental delivery, uterine massage to activate uterine contraction and assessment of uterine tonus every 15 min during $2 \mathrm{~h}$ postpartum to early identify uterine atony $[1,4-6]$. The World Health Organization (WHO) recommends AMTSL to be performed by skilled birth attendants and health workers trained in the management of pregnancy and delivery [4]. WHO recommendations regarding implementation are component-dependent: uterotonics are recommended for all delivered women. CCT is considered optional in settings with skilled birth attendants, continuous uterine massage is not recommended if prophylactic oxytocin is provided and uterine tonus surveillance is recommended for all delivered women [4, 7-9].

Almost $60 \%$ of births in low- and middle-income countries occur in rural areas outside health facilities and are assisted by traditional birth attendants or family members not (formally) trained in obstetric care. Despite attempts to increase skilled attendance at (home) deliveries, this remains challenging due to a shortage of skilled birth attendants and significant travel distances in rural areas $[10,11]$. As a consequence, the implementation of AMTSL is limited despite its paramount importance, especially in areas with low access to emergency obstetric care [5, 11-13].

In 2012, the WHO published recommendations on task shifting in maternal and newborn health care in an attempt to optimize the potential of the existing health workforce [14]. These recommendations include for example the administration of misoprostol by lay health workers to prevent postpartum hemorrhage, but don't address all components of AMTSL. The effects of task shifting of individual components of AMTSL have never been reviewed [14].

Of the AMTSL interventions, uterotonics are the most effective in terms of prevention of $\mathrm{PPH}$, although the relative contribution of each of AMTSL components has not been well-studied $[4,15]$. Oxytocin is the preferred uterotonic drug and recommended by the WHO if skilled birth attendants are available. However, as oxytocin is thermo-unstable it requires cold-chain handling which increases costs. Additionally it should be injected intramuscularly or intravenously by skilled birth attendants. Misoprostol is considered a safe, cheap and only slightly less effective alternative [16-19]. The WHO recommends the provision of misoprostol by community health workers for $\mathrm{PPH}$ prevention in rural areas and homebirths in absence of skilled attendance [4]. Community distribution of misoprostol to pregnant women for self-administration is also widely explored as an option, but currently not recommended [20-22].

The aim of this systematic review is to evaluate the evidence on the effect, women's acceptance and safety of task shifting of different components of AMTSL to unskilled birth attendants or self-administration.

\section{Methods}

\section{Protocol}

This review was designed in accordance with the PRISMA guidelines [23].

\section{Eligibility criteria \\ Type of study}

Randomized controlled trials (RCTs) or quasiexperimental trials evaluating the effect of implementation of components of AMTSL to unskilled birth attendants or delivering women on the incidence of $\mathrm{PPH}$ compared to the current situation, which is mostly no implementation of components of AMTSL at all. No restrictions on language and publication date were applied. Case reports, reviews and proceedings were excluded.

\section{Type of participants}

Women delivering in a community setting or health facility center in LMIC without skilled birth attendants present. Skilled birth attendants are defined as accredited health professionals (midwife, nurse) who are trained to assist pregnancies and postpartum care. Unskilled birth attendants are nonprofessionals, educated in a specific task of pregnancy care and postpartum care [24].

\section{Type of intervention}

Trials evaluating the effect on outcome measures of implementation of administration of uterotonics (oxytocin or misoprostol), controlled cord traction, uterine massage, assessment of uterine tonus during 2 hpostpartum to unskilled birth attendants in areas without standardized postpartum care according to AMTSL. By evaluating the effect and safety of AMTSL performed by unskilled birth attendants, effect and safety of task shifting is indirectly measured. Task shifting is defined as a process in which tasks are moved from skilled to less skilled health workers [14]. 


\section{Type of outcome measures}

The primary outcome measure was the incidence of postpartum hemorrhage, defined as blood loss of $500 \mathrm{ml}$ or more in the first $24 \mathrm{~h}$ postpartum. Secondary outcomes were women's acceptance and safety. The first defined as recommending the care to friends or family, willingness to receive the same care at their next delivery and willingness to pay for uterotonics at the next delivery. The latter defined as receiving the care at the correct time during third stage of labor and using correct methods as described in the WHO guidelines [4]. Safety also included adverse effects of interventions.

\section{Information sources}

The search was performed in the following electronic databases: The Cochrane Library (Cochrane Database of Systematic Reviews), EMBASE, Global Health Library, POPLINE and PubMed for all publications up to September 2015. Full texts were available for all included studies. In addition, included studies were screened for additional relevant studies through their reference lists and cross-referenced in Web of Science.

\section{Search}

Synonyms for 'Active Management of the Third Stage of Labor' and its components, i.e. 'uterotonics', 'cord traction,' 'uterine massage' and 'uterine tonus' combined with synonyms for 'task shifting' and correlating Mesh terms were used as search strategy. The full search strategy including a list of synonyms is available in the Additional file 1.

\section{Study selection}

After removal of duplicates, the title and abstract of retrieved studies were screened by two independent reviewers (TR, VS) using predefined inclusion and exclusion criteria. Any discrepancies between the two reviewers in this process were discussed and full text accessed if necessary for further clarification. If results were published multiple times, data were used only once from the most complete article.

\section{Data collection process and data items}

Data were extracted from each individual article using a standardized extraction form and included: study design, study setting and location, number of delivered women and population characteristics including age, parity and educational level, intervention as part of AMTSL, by whom this was performed and educational level or training received, incidence of $\mathrm{PPH}$ and relative risks with corresponding 95\% confidence interval, women's acceptance including willingness to pay for uterotonics, recommendations to friends and family and wish to receive same care or drugs at next delivery, safety including correct dose, correct time and duration of intervention and reported side effects. The extraction was performed by one reviewer (TR) and a second reviewer was available for discussion or clarification processes. Corresponding authors were contacted in case further information was required.

\section{Quality assessment}

Quality of studies was assessed at study level using an adapted version of the Cochrane Collaboration's tool for assessing risk of bias for systematic reviews of interventions [25]. Studies were scored for detection bias, evaluating blinding of participants for outcome measurements; attrition bias, evaluating completeness and origin of data; reporting bias, evaluating origin of data, definition and assessment of outcome measurements; and possible confounders. Risk of bias was assigned as low, high or unclear risk, according to the quality assessment tool, attached as a Additional file 2. Any disagreements were discussed until consensus was achieved.

\section{Summary measures}

Incidence of $\mathrm{PPH}$ was reported in relative risks (RR) and $95 \%$ confidence interval (CI). If these were not reported, they were calculated using SPSS v20.0 software [26]. Women's acceptance and safety were reported in percentages.

\section{Synthesis of results}

Results were narratively described because the heterogeneity of the interventions and settings did not allow for a meaningful meta-analysis.

\section{Results}

\section{Study selection}

The systematic search identified 2469 studies after removal of duplicates, of which 60 studies remained after title and abstract screening [Fig. 1]. Of these studies, 21 met the inclusion criteria. No additional studies were obtained through snowballing. All studies aimed to evaluate effect and safety of implementation of AMTSL to unskilled attendants compared to standard of care (mostly no standardized care). No studies were found reporting on task shifting of components of AMTSL from skilled to unskilled birth attendants.

\section{Study characteristics}

Study characteristics are presented in Tables 1 and 2 . Five studies were RCTs [11, 17, 27-29] and sixteen were quasi-experimental trials $[5,10,12,13,22,30-40]$. Studies were published between 2005 and 2014 and reported on 236 to 77.337 included pregnant women in community centers or at home births in LMIC in Africa $(48 \%, n=10)$ Asia $(43 \%, n=9)$ and Central America $(2 \%$, 


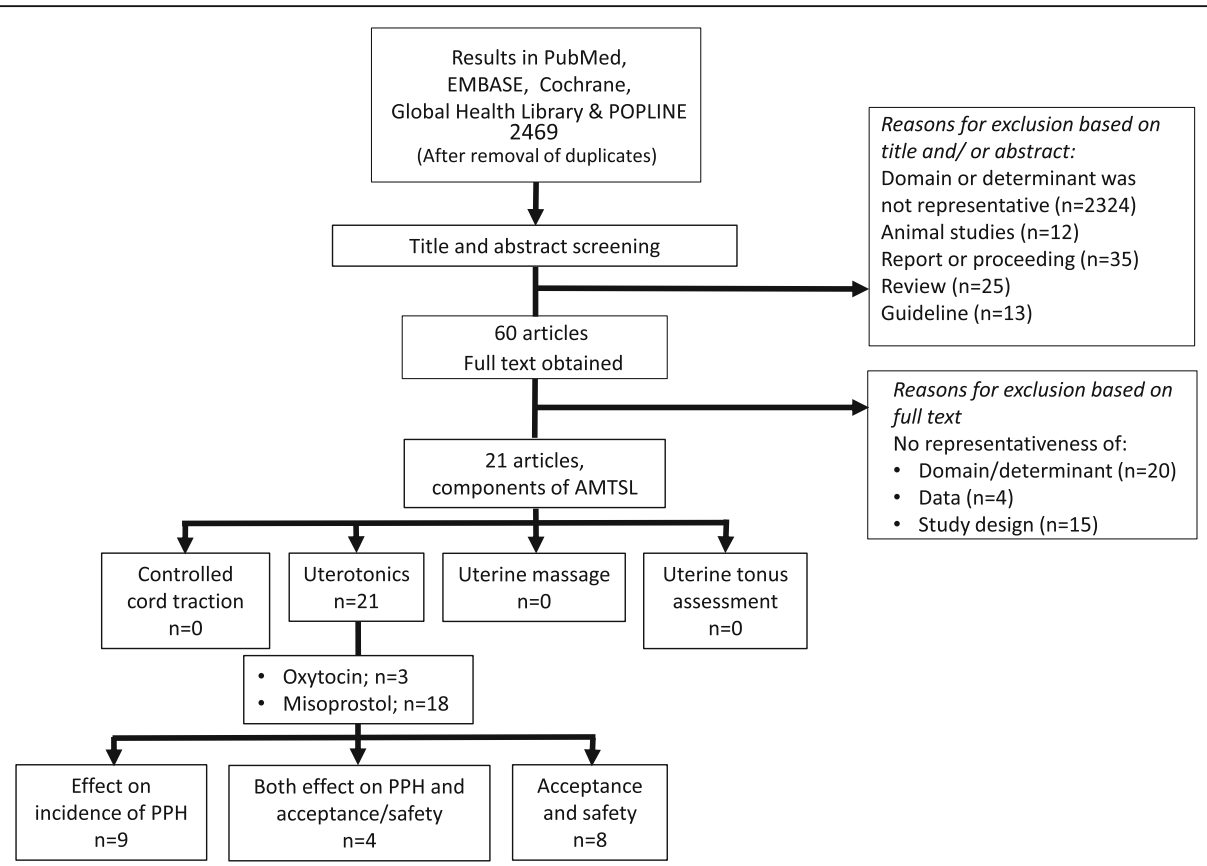

Fig. 1 Flowchart of literature search and selection process. PPH: postpartum haemorrhage

$n=2)$. Tasks were shifted to community health workers $(19 \%, n=4)$, auxiliary midwives $(19 \%, \mathrm{n}=4)$, traditional birth attendants $(38 \%, n=8)$ or self-administered by delivered women $(48 \%, \mathrm{n}=10)$.

All studies assessed the administration of uterotonics; misoprostol tablets or oxytocin injections. Misoprostol tablets for self-administration were distributed at antenatal (home) visits $(n=5)$, at delivery $(n=12)$ or both $(n=4)$. Controlled cord traction, uterine massage and uterine tone assessment and their effect on reduction of PPH were not reported in any of the studies. Therefore the main focus of the remainder of this article will be on task shifting of uterotonic admission.

\section{Risk of bias within studies}

The overall risk assessment is summarized in Fig. 2, the individual study risk of bias assessment is available as a Additional file 2.

\section{Detection bias}

In $14 \%(n=3)$ of 21 studies both delivered women as participants were blinded for intervention and outcome. In one study the outcome was measured by workers who were not involved in the distribution process. In the remaining studies participants performing the intervention were also involved in the measurement of outcomes. In none of the articles a bias effect is mentioned and because of possible influence on outcomes, risk of bias was scored as unclear.

\section{Attrition bias}

Data on baseline characteristics were obtained at antenatal care visits in facility centers or during home visits. Data on intervention and outcome measures were obtained at delivery by auxiliary midwives, community health workers or traditional birth attendants by interviewing women postpartum. All health workers received training on how to collect data and therefore low risk of bias for origin of data was scored. In $81 \%(n=17)$ of studies were less than $10 \%$ missing data of outcome measures or loss to follow up and therefore low risk of bias on completeness of data was scored. One article had more than $10 \%$ missing data [22].

\section{Reporting bias}

In $86 \%(n=18)$ of articles the definition of $\mathrm{PPH}$ was clear. In the other articles PPH was defined as 'need for referral' or 'heavy bleeding'. Blood loss was objectively measured in $62 \%(n=8)$ of studies with a calibrated scale. In $38 \%(n=5)$ of studies blood loss was visually estimated by health workers or blood loss was subjectively estimated by delivered women and was therefore scored as a high risk of bias. PPH was not measured in eight articles and scored as 'not applicable'.

\section{Possible confounders}

Confounders were scored as low risk of bias in randomized controlled trials without differences in baseline characteristics. In $71 \%(n=15)$ of studies possible confounders were not reported and therefore risk of bias was scored 'unclear'. 


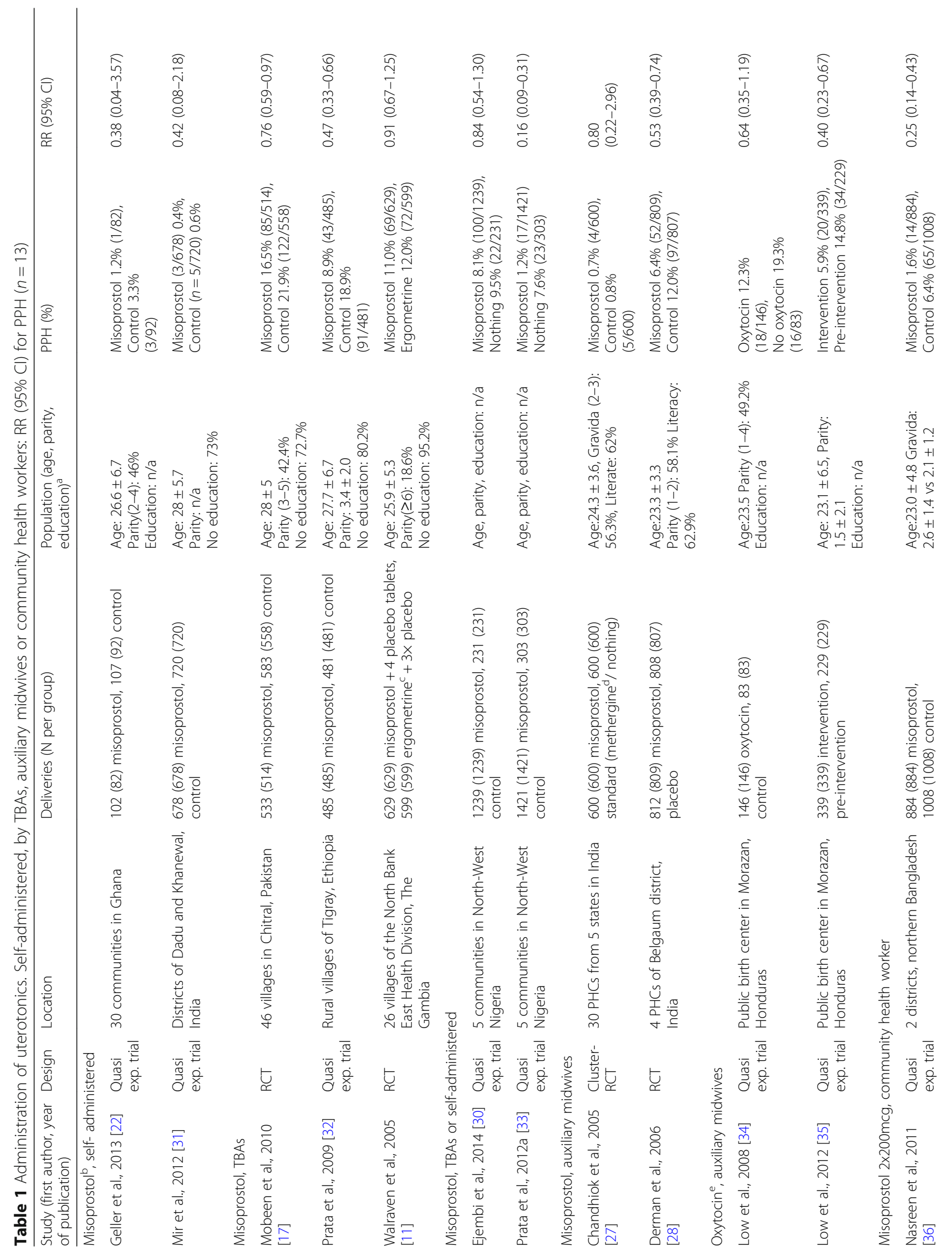




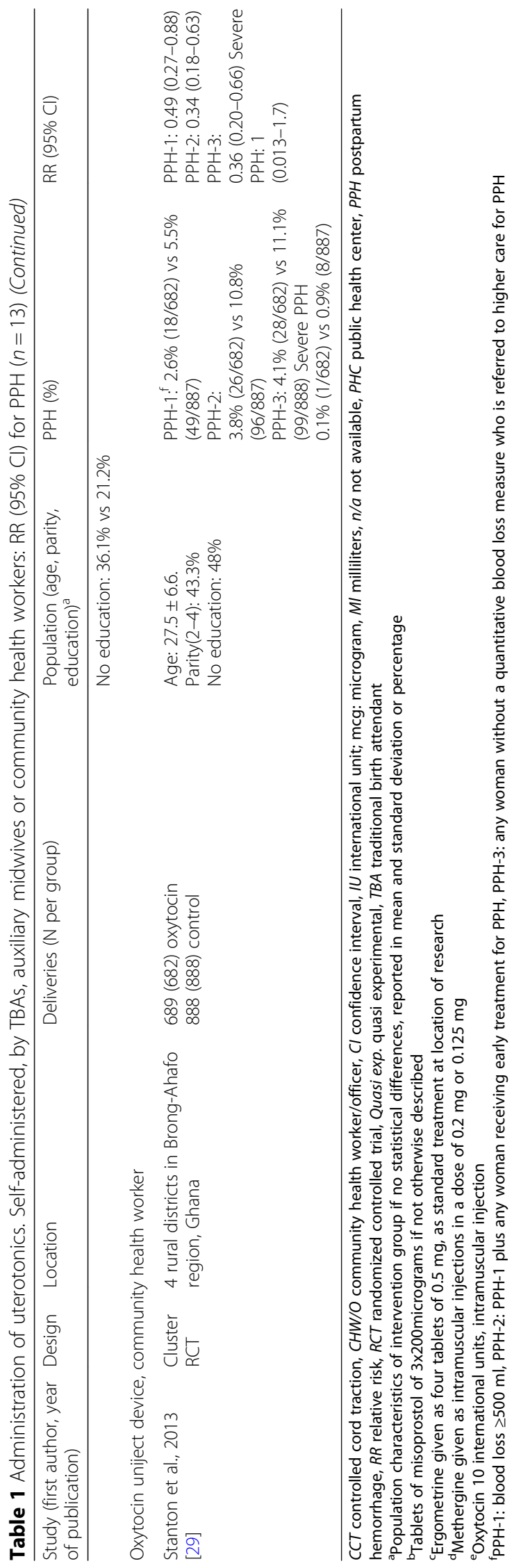




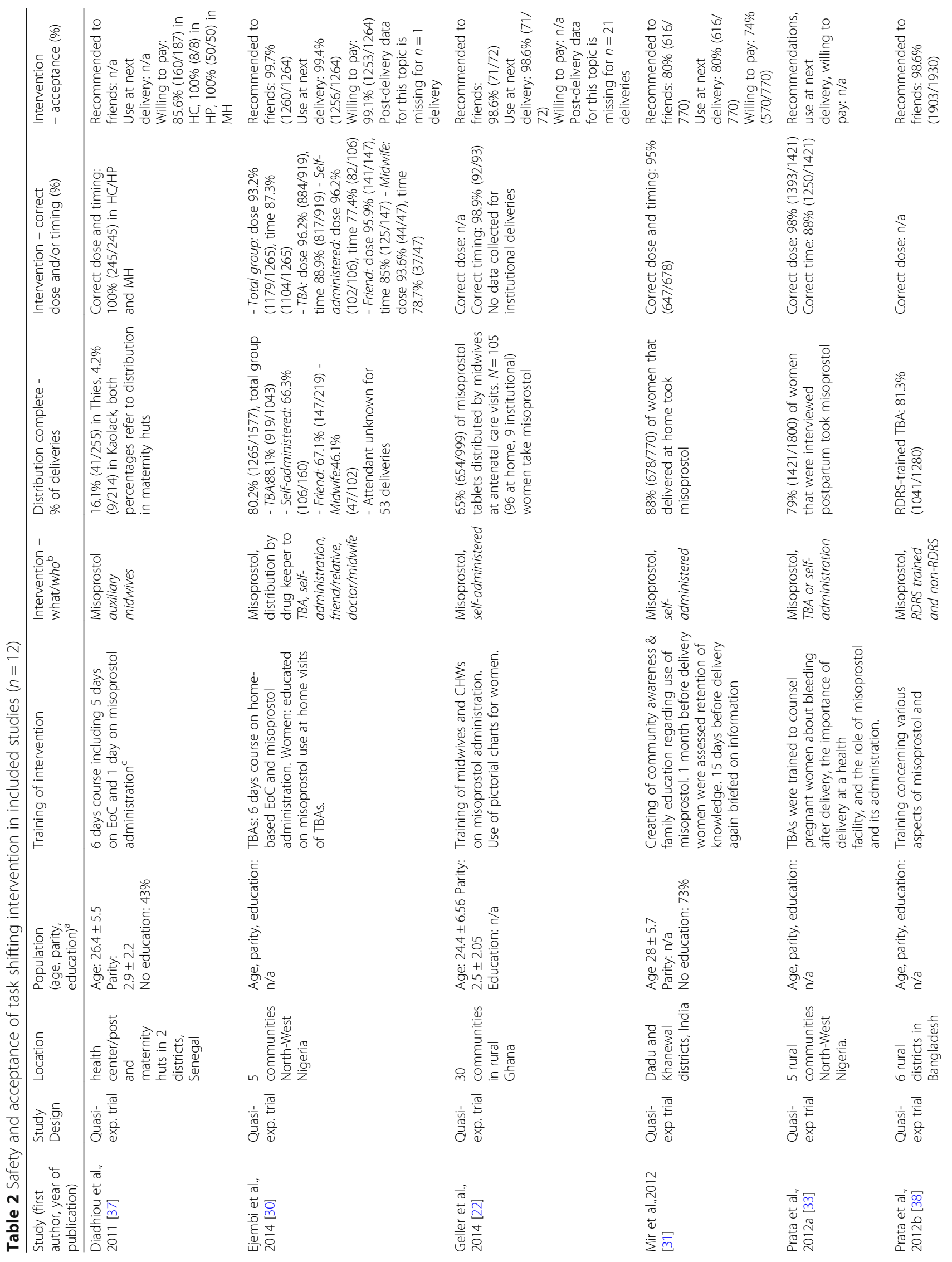




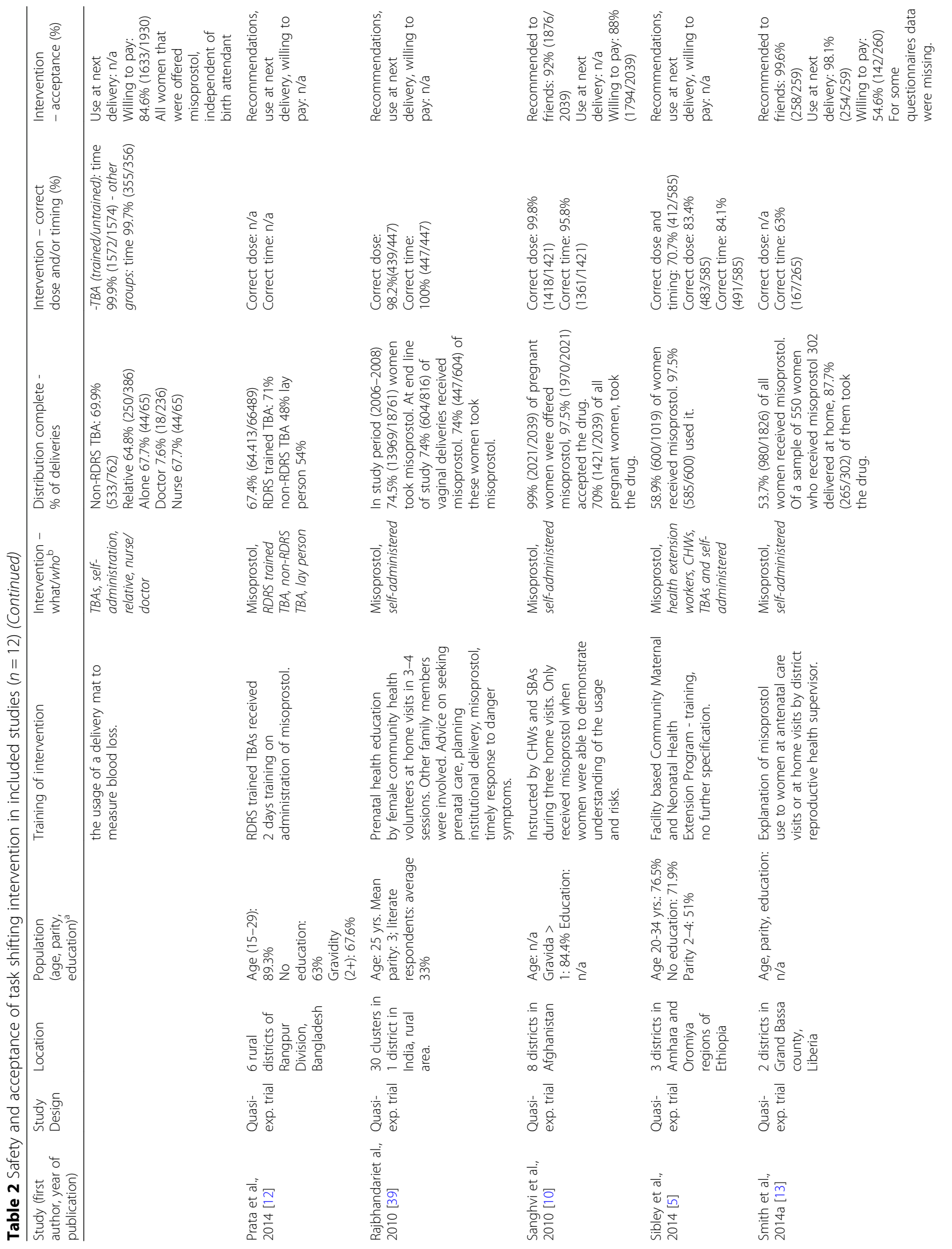




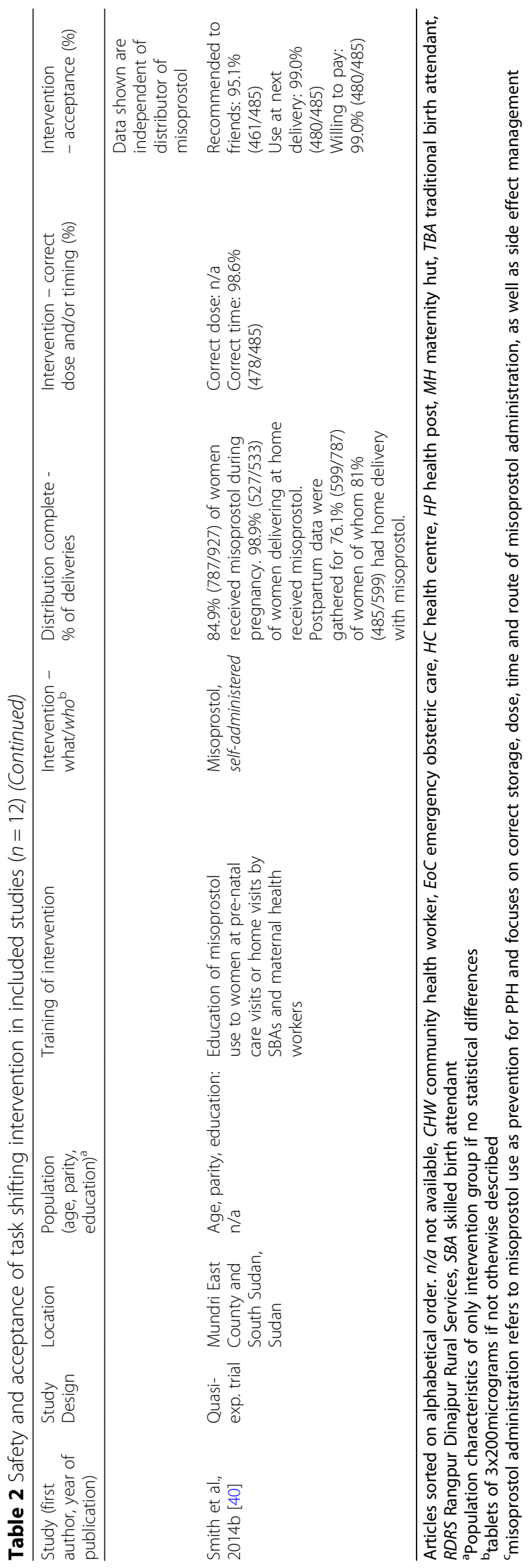




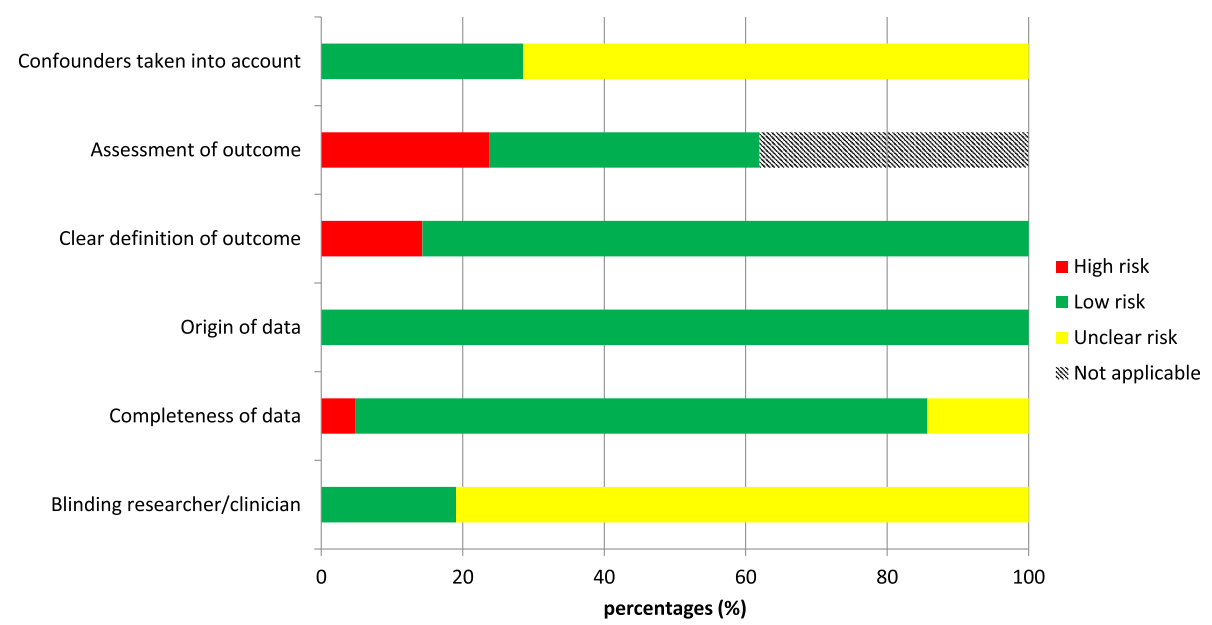

Fig. 2 Bar graph showing the risk distribution according to the different variables on which 21 articles were assessed. Blinding of researcher/clinician was only evaluated if intervention was compared to control group

\section{Results of individual studies \\ Primary outcome: PPH incidence}

In thirteen studies (15.197 women), the primary outcome assessed was the incidence of $\mathrm{PPH}$ when uterotonics were provided by unskilled birth attendants.

The incidence of $\mathrm{PPH}$ in delivered women who received misoprostol tablets $(n=10)$ was compared to the incidence in women treated by the standard care of no uterotonics $(n=8)$, ergometrine $(n=1)$ or methergine $(n=1)$. Intramuscular oxytocin injections (10 international units) were provided in three studies, in one of these a Uniject device, a disposable automatic syringe, was used. Oxytocin was administered by auxiliary midwives or community health workers. The relative risks of $\mathrm{PPH}$ incidence varied from 0.16 to 1 in favor of task shifting. For seven of thirteen articles relative risks were statistically significant $[17,28,29,32,33,35,36]$.

In all studies, educational programs were organized before the start of the interventional trial. Most educational programs for community health workers, auxiliary midwives or traditional birth attendants included a multiple-day course on aspects of AMTSL, mainly focusing on administration of uterotonics. Pregnant women were educated on self-administration by nurses or health workers at antenatal care visits, both at home or in a clinic.

\section{Secondary outcome: Acceptance and safety of task shifting} In twelve studies $[5,10,12,13,22,30,31,33,37-40]$ the primary outcome assessed was women's acceptance and safety of community distribution of uterotonics [Table 2]. In all studies administration of uterotonics was evaluated.

\section{Women's acceptance}

Of delivered women who self-administered misoprostol tablets postpartum or received tablets from traditional birth attendants, $80 \%$ to $99.7 \%$ (7 studies, 6445 women) recommended taking misoprostol tablets at delivery to family or friends. Approximately the same percentage, $80 \%$ to $99.4 \%$ (5 studies, 2677 women), would use misoprostol at their next delivery and $54.6 \%$ to $100 \%$ (7 studies, 6090 women) were willing to pay for the tablets. Of delivered women who received tablets from auxiliary midwives, $85.6 \%$ to $100 \%$ (1 study, 218 women) were willing to pay for tablets. No data were available for women who received tablets from community health workers.

\section{Safety of intervention}

Of delivered women who self-administered misoprostol tablets or received tablets from traditional birth attendants $83.4 \%$ to $99.8 \%$ (5 studies, 4719 women) took misoprostol tablets at the correct dose and $63 \%$ to $100 \%$ (9 studies, 6757 women) took tablets at the correct time, after delivery of the baby and before placental delivery. Both correct dose and time was mentioned in two articles and achieved by $70.7 \%$ to $95 \%$ of women $(n=1304)$. Approximately the same percentages were observed for auxiliary midwives and community health workers, 83.4\% (1 study, 483 women) took the correct dose, $84.1 \%$ (1 study, 491 women) at the correct time. Both correct dose and time was mentioned in two articles and achieved by $70.7 \%$ to $100 \%$ of women $(n=657)$. Incorrect use of misoprostol mostly included taking a lower dose or waiting too long for taking the tablets. Eight articles explicitly described that misoprostol was not taken before delivery of the baby, in one article less than 
$2 \%$ of the pregnant women took misoprostol pre-infant delivery.

\section{Adverse effects of uterotonics}

Adverse effects of misoprostol or oxytocin in the community setting were mentioned in fourteen articles $[10,11,13,17,22,27,28,30,31,32,36,37,39,40$, Additional file 3]. Mild-to-moderate adverse effects of misoprostol included nausea, vomiting, shivering and/or fever. There were no significant differences in these adverse effects between intervention and control groups of no uterotonics, ergometrine ( $n=1$ study) or methergine ( $n=1$ study).

\section{Discussion}

This systematic review about task shifting within AMTSL interventions shows that only administration of uterotonics has been evaluated in community and health facility settings in low- and middle-income countries. No data are available for task shifting of controlled cord traction, uterine massage or uterine tone assessment and its effect on incidence of $\mathrm{PPH}$.

Compared to no AMTSL, the administration of uterotonics by traditional birth attendants, auxiliary midwives, community health workers or the woman herself reduced the incidence of PPH. Task shifting of this part of AMTSL to unskilled birth attendants was generally accepted by women and care providers and was reported to be a safe intervention.

Community distribution of misoprostol and oxytocin by auxiliary midwives and lay health workers as a strategy to increase uterotonic coverage is currently included in WHO guidelines on the prevention of postpartum hemorrhage [4]. The results of this review confirm the safety and effectiveness of this strategy. Administration of misoprostol or oxytocin self-administered by delivered women is not yet recommended in WHO guidelines, and could be considered a strategy to further increase access to AMTSL.

A number of challenges in improving the implementation of AMTSL through task shifting have been suggested. First, misoprostol can be used as an abortifacient and mistimed administration could lead to premature deliveries [39]. Although misoprostol is recognized as an essential medicine by the WHO, worries of mistimed administration have prevented the registration in many countries [41]. While no data were available for number of abortions or preterm deliveries, this remains a potential serious side effect of mistimed administration of misoprostol. The results of this study show that the vast majority of women took or received tablets at the correct time and in the correct dose. In addition, programs that encourage return of misoprostol tablets in case it was not used (e.g. in facility delivery where oxytocin was available), had a near-complete recovery rate [22]. Our results are in line with a systematic review of Smith et al. [42], who described strategies and their safety when distributing misoprostol in the community. They identified 18 studies and showed that $0.06 \%(n=7)$ of 12.615 women incorrectly used misoprostol. No significant differences were seen for the number of stillbirths or neonatal deaths in case uterotonics were provided.

Secondly, an emphasis on task shifting elements of AMTSL could send a mixed-message and may inadvertently stimulate pregnant women to deliver at home without skilled birth attendants. Therefore, the message should always be to promote facility based delivery and only use pragmatic rescue treatment if other options fail. As such, task shifting could be considered complementary in creating community awareness as an intermediate solution towards universal facility based deliveries. In fact, introducing misoprostol distribution programs and associated education training programs for implementation have been reported to increase awareness of the importance of medical care and referrals to Emergency Obstetric Care facilities [7, 31]. Prata et al. [38] observed that level of training is directly proportional to distribution rates of uterotonics, emphasizing the importance of education in creating community awareness. An additional advantage of an intense training program with task shifting of AMTSL to community health workers and traditional birth attendants may be to increase their awareness about referral indications and provide a bridge between community-based traditional care and facility-based obstetric care [7]. Task shifting of AMTSL may also provide an opportunity for facility-based obstetric care to improve quality of care in light of the continuing shortage of skilled birth attendants and to reduce workload for midwives. For example, a randomized controlled trial in a tertiary hospital in Ghana (clinicaltrials.gov, registration number: NCT02223806; [43]) suggested that the final step of postpartum assessment of the uterine tonus can be effectively conducted by patients, whilst regularly monitored by midwives (unpublished data). Recent evidence indicates that omission of CCT has little effect on the risk of severe hemorrhage and the WHO recommends not to include CCT in hemorrhage prevention programs for nonhospital settings $[8,9]$.

Strengths of this review include the broad focus to include multiple components of AMTSL. In contrast to earlier reviews, we did not only focus on the effect on $\mathrm{PPH}$ incidence and safety, but also included women's acceptance of the interventions [20, 42]. Limitations include our inability to conduct a meta-analysis due to heterogeneity of interventions, outcome measurements and contexts. Data were collected at antenatal care 
visits, during delivery or a few days or weeks postpartum by health workers or traditional birth attendants. Postpartum hemorrhage was measured using different methods varying from visual estimation to using a calibrated scale, possibly explaining the high differences in incidence of PPH between the included studies. Additional file 2 provides more detailed information on measurements of postpartum hemorrhage among the different studies. Educational programs differed between studies, varying from 1-day programs to 7-day programs which is likely to influence the level of skills. An additional limitation is that we only included peerreviewed literature, which may have excluded intervention reports from the grey literature, for example from non-governmental organizations working in LMIC. All studies evaluating the safety of community distribution of misoprostol, compared reduction of $\mathrm{PPH}$ to standard care, which is (mostly) no use of uterotonics. No trials exist comparing the effect on PPH of uterotonics by unskilled birth attendants compared to administration by skilled attendants. However, by not only focusing on the effect of uterotonic administration itself but by also evaluating the effect and safety of task shifting in rural areas, this systematic review has also included safety and acceptance of community distribution.

This review supports the growing body of evidence that the potential of human resources should be maximized at all levels of the health-care system to reduce the burden of maternal morbidity and mortality. In line with this the Senegal Ministry of Health agreed in their national strategic plan for 2014-18 that misoprostol could be provided by auxiliary midwives in maternity huts [44]. In the prevention of $\mathrm{PPH}$ as major contributor to maternal mortality, the efficacy and safety of task shifting of all elements (except for controlled cord traction, which is discouraged by the WHO in case skilled birth attendants are absent) within AMSTL should be evaluated in future studies.

\section{Conclusion}

Task shifting of (parts of) AMSTL to community health workers, traditional birth attendants or selfadministration has been explored in response to the shortages in skilled birth attendants and facility-based deliveries in low- and middle income countries. This systematic review showed that so far only task shifting in uterotonics (oxytocin and misoprostol) administration has been reported. The administration of misoprostol tablets by CHWs, traditional birth attendants or self-administered proved to be effective, safe and accepted in low resource settings. The administration of intramuscular oxytocin by CHWs and auxiliary midwives proved to be effective in reducing PPH. Educational programs are the key element for improvement of implementation of AMTSL and creating awareness of importance of timely referral for emergency obstetric care. As a comprehensive PPH-reduction-strategy based on the AMTSL requires implementation of all steps (except for controlled cord traction, which is discouraged by the WHO in case skilled birth attendants are absent) expanding task shifting to other relevant components of AMTSL will provide additional opportunities to prevent maternal morbidity and mortality due to $\mathrm{PPH}$.

\section{Additional files}

Additional file 1: Full search strategy and list of synonyms. (DOCX $19 \mathrm{~kb}$ ) Additional file 2: Individual study risk of bias assessment, according to quality assessment tool. (XLSX $16 \mathrm{~kb}$ )

Additional file 3: Side effects of misoprostol during pregnancy / delivery $(n=14)$. (DOCX $17 \mathrm{~kb})$

\section{Abbreviations}

AMTSL: Active management of the third stage of labor; CCT: Controlled cord traction; CHW: Community health worker; Cl: Confidence interval;

EOC: Emergency obstetric care; FIGO: International federation of gynecology and obstetrics; ICM: International confederation of midwives; LMIC: Low- and middle income country; Ml: Milliliters; PPH: Postpartum hemorrhage; RR: Relative risk; SBA: Skilled birth attendant; TBA: Traditional birth attendant; WHO: World Health Organization

\section{Acknowledgements}

No acknowledgements are added.

\section{Funding}

Not applicable

\section{Availability of data and materials}

Details of availability of data and materials are added to Additional files 1 and 2 .

\section{Authors' contributions}

TMR conceived the research question, participated in search and selection of articles, and drafted the first version of the manuscript. JLB co-conceived the research question, was involved in the design and coordination of the study, drafting and revising the manuscript. VJMMS participated in selection of articles and revision of the manuscript. KKG co-conceived the research question and the study design, and revised the manuscript critically. MJR has been involved in coordination of the study process, drafting and revising the manuscript. All authors have approved the final version of the manuscript to be published.

Ethics approval and consent to participate Not applicable

\section{Consent for publication}

Not applicable

\section{Competing interests}

Marcus J Rijken, one of the co-authors of this systematic review, is a member (associate editor) of the editorial board of BMC Pregnancy and Childbirth.

\section{Publisher's Note}

Springer Nature remains neutral with regard to jurisdictional claims in published maps and institutional affiliations. 


\section{Author details}

'Julius Global Health, Julius Center for Health Sciences and Primary Care, University Medical Center Utrecht, Heidelberglaan 100, 3584 Utrecht, The Netherlands. ${ }^{2}$ Division of Epidemiology \& Biostatistics, School of Public Health, Faculty of Health Sciences, University of the Witwatersrand, Johannesburg, South Africa. ${ }^{3}$ Department of Obstetrics and Gynecology, University Medical Center Utrecht, Utrecht, The Netherlands.

Received: 30 July 2016 Accepted: 29 January 2018 Published online: 06 February 2018

\section{References}

1. Sheldon WR, Blum J, Vogel JP, Souza JP, Gülmezoglu AM, Winikoff B, Postpartum haemorrhage management, risks, and maternal outcomes: findings from the World Health Organization multicountry survey on maternal and newborn health. BJOG. 2014;121(Suppl):5-13.

2. Breu F, Guggenbichler S, Wollmann J. World health statistics 2013. Vasa. 2013;168

3. Lalonde A, Daviss BA, Acosta A, Herschderfer K. Postpartum hemorrhage today: ICM/FIGO initiative 2004-2006. Int J Gynaecol Obstet. 2006;94:243-53.

4. Dept. of Reproductive Health and Research. World Health Organization, dept. of reproductive health and research, World Health Organization. WHO recommendations for the prevention and treatment of postpartum haemorrhage. Geneva: World Health Organization Press; 2012.

5. Sibley LM, Spangler SA, Barry D, Tesfaye S, Desta BF, Gobezayehu AG. A regional comparison of distribution strategies and women's awareness, receipt, and use of misoprostol to prevent postpartum hemorrhage in rural Amhara and Oromiya regions of Ethiopia. J Midwifery Womens Health. 2014;59(Suppl 1):S73-82.

6. Lalonde A. Prevention and treatment of postpartum hemorrhage in lowresource settings. Int J Gynaecol Obstet. 2012;117:108-18.

7. Geller SE, Adams MG, Kelly PJ, Kodkany BS, Derman RJ. Postpartum hemorrhage in resource-poor settings. Int J Gynaecol Obstet. 2006:92:202-11.

8. Gülmezoglu AM, Lumbiganon P, Landoulsi S, Widmer M, Abdel-aleem H, Festin $\mathrm{M}$, et al. Active management of the third stage of labour with and without controlled cord traction : a randomised, controlled, non-inferiority trial. Lancet Elsevier Ltd. 2007;379:1721-7.

9. Hofmeyr GJ, Mshweshwe NT, Gülmezoglu AM. Controlled cord traction for the third stage of labour (review). Cochrane Database Syst Rev 2015, issue 1. Art. no. : CD008020.

10. Sanghvi H, Ansari N, Prata NJV, Gibson H, Ehsan AT, Smith JM. Prevention of postpartum hemorrhage at home birth in Afghanistan. Int Fed Gynecol Obstet. 2010;108:276-81.

11. Walraven G, Blum J, Dampha Y, Sowe M, Morison L, Winikoff B, et al. Misoprostol in the management of the third stage of labour in the home delivery setting in rural Gambia: a randomised controlled trial. BJOG An Int. J. Obstet. Gynaecol. 2005;112:1277-83.

12. Prata N, Bell S, Holston M, Quaiyum MA. Is attendant at delivery associated with the use of interventions to prevent postpartum hemorrhage at home births? The case of Bangladesh. BMC Pregnancy Childbirth. 2014;14:24.

13. Smith JM, Baawo SD, Subah M, Sirtor-Gbassie V, Howe CJ, Ishola G, et al. Advance distribution of misoprostol for prevention of postpartum hemorrhage (PPH) at home births in two districts of Liberia. BMC Pregnancy Childbirth. 2014;14:189.

14. World Health Organization. Optimizing health worker roles to improve access to key maternal and newborn health interventions through task shifting. Geneva: World Health Organization; 2012.

15. Prata N, Bell S, Weidert K. Prevention of postpartum hemorrhage in lowresource settings: current perspectives. Int J Womens Health. 2013;5:737-52.

16. Miller $S$, Lester $F$, Hensleigh P. Prevention and treatment of postpartum hemorrhage: new advances for low-resource settings. J Midwifery Womens. Health. 2004:49:283-92

17. Mobeen N, Durocher J, Zuberi N, Jahan N, Blum J, Wasim S, et al. Administration of misoprostol by trained traditional birth attendants to prevent postpartum haemorrhage in homebirths in Pakistan: a randomised placebo-controlled trial. BJOG. 2011;118:353-61.

18. Tunçalp Ö, Hofmeyr GJ, Gülmezoglu AM. Prostaglandins for preventing postpartum haemorrhage. Cochrane Database Syst Rev. 2012;8:CD000494.

19. Gulmezoglu AM, Villar J, Ngoc NT, Piaggio G, Carroli G, Adetoro L, et al. WHO multicentre randomised trial of misoprostol in the management of the third stage of labour. Lancet. 2001;358:689-95.
20. Oladapo OT, Fawole B, Blum J, Abalos E, Ot O, Fawole B, et al. Advance misoprostol distribution for preventing and treating postpartum haemorrhage ( review ). Cochrane Database Syst Rev. 2012;2:CD009336.

21. Prata N, Passano P, Bell S, Rowen T, Potts M. New hope: community-based misoprostol use to prevent postpartum haemorrhage. Health Policy Plan. 2013;28:339-46.

22. Geller S, Carnahan L, Akosah E, Asare G, Agyemang R, Dickson R, et al. Community-based distribution of misoprostol to prevent postpartum haemorrhage at home births : results from operations research in rural Ghana. BJOG An Int J Obstet Gynaecol. 2014;121:319-26.

23. Liberati A, Altman DG, Tetzlaff J, Mulrow C, Gøtzsche PC, loannidis JPA, et al. The PRISMA statement for reporting systematic reviews and meta-analyses of studies that evaluate health care interventions: explanation and elaboration. PLoS Med. 2009:6(7):e1000100.

24. World Health Organization. Making pregnancy safer : the critical role of the skilled attendant a joint statement by WHO, ICM and FIGO. Geneva: World Health Organization; 2004

25. Higgins JPT, Green S (editors). Cochrane Handbook for Systematic Reviews of Interventions Version5.1.0 [updated March 2011]. The Cochrane Collaboration, 2011. Available from http://handbook.cochrane.org.

26. Field A. Discovering statistics using IBM SPSS statistics. Discov. Stat. Using IBM SPSS stat. hichester: Wiley; 2013. p. 297-321.

27. Chandhiok N, Dhillon BS, Datey S, Mathur A, Saxena NC. Oral misoprostol for prevention of postpartum hemorrhage by paramedical workers in India. Int J Gynecol Obstet. 2006;92:170-5.

28. Derman RJ, Kodkany BS, Goudar SS, Geller SE, Naik VA, Bellad MB, et al. Oral misoprostol in preventing postpartum haemorrhage in resource-poor communities: a randomised controlled trial. Lancet. 2006:368:1248-53.

29. Stanton CK, Newton S, Mullany LC, Cofie P, Tawiah Agyemang C, Adiibokah E, et al. Effect on postpartum hemorrhage of prophylactic Oxytocin (10 IU) by injection by community health officers in Ghana: a community-based. Cluster-Randomized Trial PLoS Med. 2013:10

30. Ejembi C, Shittu O, Moran M, Adiri F, Oguntunde O, Saadatu B, et al. Community-level distribution of Misoprostol to prevent postpartum hemorrhage at home births in northern Nigeria. Afr J Reprod Health. 2014;18:166-75.

31. Mir AM, Wajid A, Gull S. Helping rural women in Pakistan to prevent postpartum hemorrhage: a quasi experimental study. BMC Pregnancy Childbirth. 2012:12:120.

32. Prata N, Gessessew A, Abraha AK, Holston M, Potts M. Prevention of postpartum hemorrhage: options for home births in rural Ethiopia. Afr 」 Reprod Health. 2009;13:87-95.

33. Prata N, Ejembi C, Fraser A, Shittu O, Minkler M. Community mobilization to reduce postpartum hemorrhage in home births in northern Nigeria. Soc Sci Med Elsevier Ltd. 2012;74:1288-96.

34. Low LK, Bailey JM, Sacks E, Medina L, Piñeda HOL. Postpartum hemorrhage prevention: a case study in northern rural Honduras. J Midwifery Womens Health. 2008:53:e1-6.

35. Low LK, Bailey JM, Sacks E, Robles C, Medina L. Reduced postpartum hemorrhage after implementation of active management of the third stage of labor in rural Honduras. Int J Gynaecol Obstet. 2012;119:217-20.

36. Nasreen H-E, Nahar S, Al Mamun M, Afsana K, Byass P. Oral misoprostol for preventing postpartum haemorrhage in home births in rural Bangladesh: how effective is it? Glob Health Action. 2011:4:1-11.

37. Diadhiou M, Dieng T, Ortiz C, Mall I, Dione D, Sloan NL. Introduction of misoprostol for prevention of postpartum hemorrhage at the community level in Senegal. Int Fed Gynecol Obstet. 2011;115:251-5.

38. Prata N, Quaiyum MA, Passano P, Bell S, Bohl DD, Hossain S, et al. Training traditional birth attendants to use misoprostol and an absorbent delivery mat in home births. Soc Sci Med. 2012;75:2021-7.

39. Rajbhandari S, Hodgins S, Sanghvi H, McPherson R, Pradhan YV, Baqui AH. Expanding uterotonic protection following childbirth through communitybased distribution of misoprostol: operations research study in Nepal. Int Fed Gynecol Obstet. 2010;108:282-8.

40. Smith JM, Dimiti A, Dwivedi V, Ochieng I, Dalaka M, Currie S, et al. Advance distribution of misoprostol for the prevention of postpartum hemorrhage in South Sudan. Int Fed Gynecol Obstet. 2014;127:183-8.

41. Smith HJ, Colvin CI, Richards E, Roberson J, Sharma G, Thapa K et al. Programmes for advance distribution of misoprostol to prevent post- 
partum haemorrhage: a rapid literature review of factors affecting implementation. Health Policy Plan. 2015:1-12

42. Smith JM, Gubin R, Holston MM, Fullerton J, Prata N. Misoprostol for postpartum hemorrhage prevention at home birth: an integrative review of global implementation experience to date. BMC Pregnancy Childbirth. 2013;13:44.

43. Browne JL, Damale NK, Raams TM, Van der Linden EL, Maya ET, Doe R, et al. Uterine tonus assessment by midwives versus patient self-assessment in the active management of the third stage of labor (UTAMP): study protocol for a randomized controlled trial. Trials. 2015:1-6.

44. Diop A, Daff B, Sow M, Blum J, Diagne M, Sloan NL, et al. Oxytocin via Uniject (a prefilled single-use injection) versus oral misoprostol for prevention of postpartum haemorrhage at the community level: a clusterrandomised controlled trial. Lancet Glob Health. 2016;4:e37-44. A

Submit your next manuscript to BioMed Central and we will help you at every step:

- We accept pre-submission inquiries

- Our selector tool helps you to find the most relevant journal

- We provide round the clock customer support

- Convenient online submission

- Thorough peer review

- Inclusion in PubMed and all major indexing services

- Maximum visibility for your research

Submit your manuscript at www.biomedcentral.com/submit
Biomed Central 